DOI 10.5216/ia.v45i3.63980

\title{
A PESQUISA COMO ARTICULADORA DAS PRÁTICAS PEDAGÓGICAS: CONTRIBUIÇÕES DE UM PROCESSO FORMATIVO
}

\author{
Karla Mendonça MENEZES \\ Universidade Federal de Santa Maria (UFSM), Santa Maria, Rio Grande do Sul, \\ Brasil \\ Carolina Braz Carlan Rodrigues \\ Universidade Federal de Santa Maria (UFSM), Santa Maria, Rio Grande do Sul, \\ Brasil \\ VANESSA CANDITO \\ Universidade Federal do Rio Grande Do Sul (UFRGS), Rio Grande, Rio Grande \\ do Sul, Brasil \\ Félix AleXANdRe Antunes Soares \\ Universidade Federal de Santa Maria (UFSM), Santa Maria, Rio Grande do Sul, \\ Brasil
}

\begin{abstract}
Resumo: Este estudo investigou as contribuições de uma proposta de formação continuada tendo a pesquisa como articuladora do processo de ensinoaprendizagem. O percurso metodológico esteve orientado pela pesquisa-ação e perpassou um processo formativo, desenvolvido com 25 professores de uma escola da rede pública estadual do Rio Grande do Sul. As observações evidenciaram a pesquisa pedagógica como uma alternativa promissora para melhoria do processo de ensino-aprendizagem, pois possibilitou um espaço significativo de interlocução entre os participantes e para a identificação das necessidades e interesses da comunidade escolar. Os processos empregados promoveram espaço e tempo para formação dos docentes dentro da instituição de ensino e corroboraram as potencialidades do trabalho colaborativo escolauniversidade.
\end{abstract}

Palavras-chave: Formação docente. Práticas educativas. Pesquisa-ação. Trabalho colaborativo.

\section{INTRODUÇÃO}

A formação de professores tem sido foco de muitas discussões nas últimas décadas, sendo considerada um processo permanente de desenvolvimento e componente integrante do exercício profissional. Assim, a formação continuada é entendida como parte do desenvolvimento profissional docente, e desenvolvida em programas promovidos dentro e/ou fora das instituições de ensino (BRASIL, 2002; SILVA et al., 2011). Inserida nesse contexto, a contribuição da pesquisa na formação e na prática docente tem se tornado tema central de grande parte das reformas educacionais 
atuais, surgindo como uma estratégia que visa romper com concepções tradicionais em busca da construção de modelos críticos de formação. Destarte, a legislação brasileira, relativa à formação de professores, também reconhece a necessidade da pesquisa no planejamento e no trabalho docente (BRASILa, 2017).

Para Nóvoa (1992), conhecer o professor desde sua formação inicial, assim como o processo pelo qual ele se constrói ao longo da sua carreira profissional, é fundamental para a compreensão das práticas pedagógicas. Neste sentido, a formação passa por processos de investigação e, portanto, é essencial encontrar espaços de debate, planejamento e análise que acentuem a colaboração entre os professores, instituindo novas relações com o saber pedagógico e científico, enfatizando a diversificação dos modelos e das práticas de formação. Freire (1996) também corrobora a pesquisa pedagógica, aliada à prática reflexiva, e salienta que a indagação, a busca, a investigação são integrantes da prática docente e, sendo assim, aponta a necessidade de que o professor se perceba e se assuma como pesquisador.

Para Lüdke et al. (2016), a reflexão sobre professores se tornarem pesquisadores da sua prática surgiu no Brasil a partir de um movimento de autocrítica, devido ao crescimento das demandas relacionadas à atividade docente. Assim, na perspectiva de uma prática reflexiva, a pesquisa pode ser compreendida como um princípio educativo que apresenta dois aspectos distintos: como caminho para novos conhecimentos ou como possibilidade de resposta a problemas já estabelecidos (LÜDKE et al., 2016).

Ao considerar essa perspectiva, as contribuições da pesquisa como instrumento de reflexão coletiva sobre a prática, é enfatizada por estudiosos que analisam as relações entre a formação de professores e a pesquisa (NÓVOA, 1992; FREIRE, 1996; IBIAPINA, 2008; DINIZ-PEREIRA, 2012; KEMMIS; WILKINSON, 2012; ZEICHNER, 2012; THIOLLENT; COLETTE, 2014; CHOW et al., 2015; GASPAROTTO; MENEGASSI, 2016; LÜDKE et al., 2016; ANDRÉ, 2017; LISITA; ROSA; LIPOVETSKY, 2017; LÜDKE, 2017). Embora utilizem termos distintos ao se referir à pesquisa dos educadores, esses estudos atribuem, sobretudo ao professor, um papel ativo no próprio processo de desenvolvimento profissional e valorizam a articulação de trabalhos entre as universidades e as escolas.

Diniz-Pereira (2012) aponta uma polissemia de termos empregados para definir a pesquisa realizada no contexto escolar. Dentre os quais, pesquisa-ação, investigação na ação, pesquisa colaborativa e práxis emancipatória apresentam-se como mais frequentes. De acordo com o autor, esses termos são utilizados para se referir à pesquisa feita por educadores, a partir de sua própria prática em sala de aula, e têm em comum a identificação de estratégias de ação que são planejadas, implementadas e sistematicamente submetidas à observação, reflexão e transformação. Fagundes (2016) também sugere que as diferentes denominações que caracterizam o professor pesquisador assentam-se sob o mesmo paradigma, qual seja, o professor que reflete sobre sua própria prática e elabora estratégias em cima dessa prática, assumindo sua realidade escolar como objeto de pesquisa, reflexão e análise.

O potencial da pesquisa em criar condições que auxiliem os docentes a refletir criticamente sobre o ensino e o contexto social no qual estão inseridos também é enfatizado nos estudos de André (2017) e Lisita; Rosa; Lipovetsky (2017). As autoras sugerem que os cursos de formação têm a função de evidenciar as possibilidades de 
MENEZES, K. M.; RODRIGUES, C. B. C.; CANDITO, V. SOARES, F. A. A.

articulação entre o ensino e a pesquisa nas práticas docentes, e assim favorecer a busca pela compreensão dos processos de aprendizagem dos escolares, a autonomia na investigação da realidade e dos conhecimentos que constituem seus objetos de estudo.

Assim, no âmbito escolar, a pesquisa permite a interação entre pesquisadores e professores, num processo de estudo teórico-prático que envolve constantes questionamentos, avaliações e reflexões sobre o trabalho docente, com o intuito de compreender melhor a realidade e construir novas práticas. Considerando esses aspectos, a identificação das necessidades e interesses da comunidade escolar emerge como alternativa para orientação e planejamento das ações pedagógicas que permitam o enfrentamento dos problemas de modo participativo. Neste contexto, a pesquisa-ação apresenta potencial enquanto ferramenta de ensino (THIOLLENT; COLETTE, 2014; ZEICHNER, 2012), estabelecendo um processo colaborativo de aprendizado que orienta os indivíduos a investigar e mudar suas realidades sociais e educacionais (KEMMIS; WILKINSON, 2012).

Sustentados por esse escopo teórico e metodológico, este estudo nos leva a refletir sobre uma experiência desenvolvida em uma escola da rede estadual de ensino do sul do país, no que se refere à formação docente, articulada pela pesquisa-ação, através de processos contínuos de investigação, ação e avaliação. Assim, o objetivo deste estudo foi analisar as contribuições de uma proposta de formação continuada, tendo a pesquisa-ação como fomentadora do processo de ensino-aprendizagem.

\section{PROCEDIMENTOS METODOLÓGICOS}

Esse estudo foi desenvolvido durante o ano letivo de 2018 e integra um conjunto de ações realizadas pelos pesquisadores em parceria com uma escola pública estadual, vinculada à $8^{\text {a }}$ Coordenadoria Regional de Educação, localizada no município de Santa Maria/RS. Os procedimentos éticos foram respeitados e a realização deste estudo aprovada pelo comitê de ética em pesquisa da Universidade Federal de Santa Maria (CAAE 40314114.8.0000.5346).

O percurso metodológico esteve orientado pela pesquisa-ação, seguindo as recomendações de Thiollent (2011). Nessa perspectiva, primeiramente se estabeleceu um diagnóstico situacional, no qual o contexto, os atores, as necessidades e as expectativas foram identificadas e, com base nesse levantamento, as ações educacionais foram planejadas.

É preciso resgatar que processos formativos, com diferentes enfoques e perspectivas, foram desenvolvidos nesse contexto escolar anteriormente, originando dissertações (ROSSI, 2014; LIMA, 2014; CARLAN, 2016) e teses (ILHA, 2014; VISINTAINER, 2018; LIMA, 2019; RODRIGUES, 2020), entre outras publicações. Esses estudos contemplaram diferentes grupos (professores e/ou estudantes) e foram essenciais para o apoio e engajamento dos gestores e do corpo docente, que concederam parte de suas reuniões pedagógicas para o planejamento conjunto de novas ações, como também para as análises e discussões contínuas dos resultados, de modo a oportunizar a reorganização do contexto curricular.

Segundo dados do Censo Escolar, no ano de 2018, a referida escola teve 166 estudantes matriculados nos anos iniciais do Ensino Fundamental, 218 nos anos finais, além de 126 estudantes no Ensino Médio (BRASIL, 2018). No início do ano letivo de 2018, 
dada a homologação da Base Nacional Comum Curricular (BRASILb, 2017), a comunidade escolar deu início a um processo de reorientação curricular. Com isso, para identificar as demandas e nortear as futuras ações, os pesquisadores, professores e coordenação pedagógica se reuniram em março de 2018. Inicialmente, as discussões tiveram como propósito resgatar as observações dos docentes sobre a comunidade escolar, a fim de investigar os interesses, objetivos e expectativas.

De acordo com Thiollent (2011), o tema de pesquisa é a designação do problema prático e das áreas de conhecimento a serem abordados. Assim, a partir do levantamento inicial, coletivamente, a educação em saúde foi delimitada como tema norteador. Em continuidade, na fase inicial da pesquisa também é essencial a definição de uma problemática, contemplada dentro de um campo teórico e prático, na qual a investigação se desenvolverá (THIOLLENT, 2011). Neste sentido, dentre as situações significativas, os professores sinalizaram a necessidade de retomar os ciclos de estudos e elegeram os temas para os encontros subsequentes.

A importância do aprofundamento teórico para gerar diretrizes para orientar a pesquisa, bem como as interpretações, também é destacado por Thiollent (2011) no desenvolvimento de uma pesquisa-ação. Por conseguinte, um ciclo de estudos foi organizado em três encontros de aprofundamento teórico envolvendo os professores, pesquisadores e profissionais convidados. Esses encontros foram realizados entre os meses de maio e julho de 2018, aos sábados, com duração de 4 horas cada. O primeiro encontro teve como tema a saúde na escola e foram discutidas as evoluções dos conceitos de saúde, educação em saúde, promoção da saúde e qualidade de vida. Duas questões foram propostas a fim de identificar as concepções dos professores sobre a educação em saúde no contexto escolar e também instigar as reflexões sobre as práticas docentes. Ao final desse encontro, foram debatidas as demandas da comunidade escolar e elencados os assuntos relevantes para os dois encontros seguintes. Os educadores apontaram para a necessidade de contemplar temas em saúde, como estilo de vida, autocuidado, hábitos alimentares e sedentarismo.

O segundo encontro, também de aprofundamento teórico, teve como tema as doenças crônicas não transmissíveis (DCNT) e as evidências para a prevenção e controle dos fatores de risco. Inicialmente, foram apresentados pelos pesquisadores alguns dados epidemiológicos nacionais e, em seguida, foram resgatados dados sobre estilo de vida dos escolares, fundamentados pelos estudos prévios realizados na escola (RODRIGUES et al., 2020). Em um segundo momento, com ênfase nos fatores de proteção ao surgimento de DCNT, uma nutricionista, convidada pelos pesquisadores, abordou tópicos sobre alimentação saudável e propôs algumas atividades pedagógicas para serem trabalhadas com os escolares. Essa atividade buscou a superação de algumas dificuldades metodológicas e também suprir a carência de conteúdos relatadas pelos docentes.

Thiollent (2011) aponta que, no intuito de corresponder aos objetivos, a pesquisa-ação deve se consolidar em ações planejadas. Nessa perspectiva, ainda no segundo encontro, os docentes se organizaram em pequenos grupos de trabalho para planejar as atividades que seriam desenvolvidas durante o ano letivo. Entre os pontos sugeridos, destacaram-se a inclusão de temas relacionados à alimentação saudável e à prática de atividade física de forma efetiva e integrada ao currículo escolar e também à 
MENEZES, K. M.; RODRIGUES, C. B. C.; CANDITO, V. SOARES, F. A. A.

capacitação dos professores para a implementação de diferentes estratégias pedagógicas. As discussões evidenciaram a necessidade de buscar apoio e engajamento dos pais para a construção de uma forma de pensar mais efetiva e voltada para as reais necessidades da comunidade escolar. Com isso, um grupo de quatro professoras, das disciplinas de Educação Física, Ciências (duas) e Língua Portuguesa, propôs o desenvolvimento de um projeto interdisciplinar de ensino-aprendizagem, a ser implementado nos segundo e terceiro trimestres letivos. Os demais docentes e a coordenação pedagógica sugeriram a realização de uma ação educativa para a conscientização, mobilização e o engajamento da comunidade escolar no desenvolvimento do projeto interdisciplinar. Essa ação foi designada "Dia da Saúde na Escola" e será detalhada posteriormente.

Entendendo que a relação entre formação de professores e a pesquisa busca estabelecer vínculos entre a compreensão do contexto, as possibilidades e dificuldades que se colocam nas práticas educativas, destaca-se a necessidade de que o professor reflita sobre suas próprias ações. Em complemento aos dois encontros anteriores, no terceiro encontro, um psicólogo, especialista em gestão e docência, mediou uma roda de conversa sobre motivação, trabalho, dificuldades e inquietações dos educadores.

Ao longo do processo formativo, esse estudo contemplou 25 professores, do Ensino Fundamental e/ou Médio, de diferentes disciplinas, com idades entre 28 e 54 anos (média 41 47,61 ), que participaram de pelo menos um dos três encontros de aprofundamento teórico. Vale destacar que todo o corpo docente da escola foi convidado pela equipe diretiva e pesquisadores a participar das reuniões, entretanto, parte dos docentes realizava atividades em outras instituições de ensino e não pôde participar de todos os momentos oportunizados. Assim, além dos pesquisadores e profissionais convidados, estiveram presentes 21 professores no primeiro encontro de aprofundamento teórico, 15 no segundo e 19 no terceiro.

Para o acompanhamento e avaliação das atividades desenvolvidas durante os encontros de aprofundamento teórico, bem como dos planejamentos e execução das propostas de trabalho, foram utilizados questionários semiestruturados, diário de campo, registro fotográfico e observação participante. No diário de campo foram registrados os momentos observados, a descrição dos participantes, espaços, acontecimentos e diálogos, assim como reflexões e discussões. Em complemento, as observações e interpretações dos pesquisadores foram registradas, juntamente ao diário de campo, através da observação participante. Após os três encontros de aprofundamento teórico, os pesquisadores acompanharam o desenvolvimento das atividades através de encontros quinzenais, com pequenos grupos de professores, em horários destinados à hora-atividade, durante o restante do ano letivo, sem interferência direta dos pesquisadores nas aulas ou no desenvolvimento das atividades.

Todas informações coletadas foram avaliadas a partir da Análise de Conteúdo de Bardin (2011), compreendendo as etapas de pré-análise, exploração do material, definição das categorias e interpretação dos apontamentos. Na definição das categorias considerou-se a forma e o conteúdo das respostas e, posteriormente, verificou-se a frequência relativa das aparições das palavras e dos temas relacionados, sendo cada resposta enquadrada em apenas uma categoria. Quando considerados os aspectos quantitativos, é preciso destacar que as questões utilizadas nessa investigação foram aplicadas em três momentos diferentes. Assim, quando apresentadas em percentuais, as 
categorias foram balizadas pelo número total de professores presentes ao encontro. Destaca-se ainda que, quando necessário, foram inseridos trechos das respostas dos docentes - em itálico para diferenciar das citações de outros autores - uma vez que fornecem importantes pontos para discussão, além de permitirem interpretações complementares por parte dos leitores. Todavia, a identificação dos participantes foi preservada.

\section{RESULTADOS E DISCUSSÕES}

Esse estudo se propôs a analisar os processos de formação docente, articulados pela pesquisa-ação, a partir de uma experiência colaborativa entre os pesquisadores e uma escola da rede estadual de ensino do sul do país. É importante destacar que a experiência profissional dos docentes investigados se estende de três a 18 anos de atuação na rede de ensino pública estadual. No entanto, quando questionados sobre os momentos e espaços de formação sobre temáticas de saúde, $91 \%$ dos professores responderam não ter recebido subsídios na formação inicial. Quando questionados sobre os momentos de formação continuada, $83 \%$ dos docentes responderam ter participado de algum tipo de curso e/ou capacitação nos últimos cinco anos e, quando interrogados sobre os subsídios para abordar temas de saúde no contexto escolar, $58,33 \%$ responderam que temas de saúde foram contemplados somente nas atividades desenvolvidas na escola pelos pesquisadores.

Nesse sentido, compreender as concepções de saúde que permeiam o ambiente escolar, advindas dos conceitos elaborados pelos educadores e demais profissionais que ali atuam, pode favorecer o entendimento das ações desenvolvidas nesse contexto. Assim, no primeiro encontro de aprofundamento teórico, buscou-se identificar as concepções já estabelecidas dos docentes sobre "saúde". Por meio da análise de conteúdo, as respostas foram classificadas em quatro categorias que estão apresentadas na Tabela 1.

\begin{tabular}{cc}
\hline & Tabela 1 - Concepções de saúde dos professores \\
\hline Categoria & Conteúdo das respostas \\
\hline $\begin{array}{c}\text { Biomédica } \\
(4,76 \%)\end{array}$ & Ausência de doença \\
$\begin{array}{c}\text { Comportamentalista } \\
(14,29 \%)\end{array}$ & A saúde está diretamente ligada a hábitos e comportamentos \\
$\begin{array}{c}\text { Biopsicológica } \\
(28,57 \%)\end{array}$ & Estado de bem-estar físico e mental \\
Biopsicossocial & Estado de bem-estar físico, mental e social \\
$(52,38 \%)$ & Compreensão de diversos fatores que contribuem para a qualidade de \\
vida
\end{tabular}


MENEZES, K. M.; RODRIGUES, C. B. C.; CANDITO, V. SOARES, F. A. A.

Ao considerar as concepções de saúde dos docentes investigados, observamos uma ínfima parcela de respostas que remeteram ao processo saúde-doença como aspectos antagônicos, inseridas na categoria Biomédica. $\mathrm{Na}$ categoria comportamentalista foram consideradas as respostas que enfatizaram a criação de "hábitos saudáveis", valorizando o aspecto comportamental, em detrimento da compreensão dos fatores intervenientes. Nas categorias Biopsicológica e Biopsicossocial as respostas remeteram a um conceito ampliado de saúde. No entanto, foram organizadas em categorias distintas, uma vez que algumas respostas, inseridas na categoria Biopsicológica, desconsideraram os aspectos sociais, enquanto respostas da categoria Biopsicossocial enfatizaram a compreensão dos diversos fatores que contribuem para a melhoria da qualidade de vida.

Quando questionados sobre "Quais são os objetivos relacionados ao tema saúde no ambiente escolar?", os professores apontaram um papel determinante da escola na promoção de estilos de vida saudáveis, como também na prevenção de doenças. As respostas foram organizadas em três categorias apresentadas na Tabela 2.

\begin{tabular}{cc}
\hline \multicolumn{2}{c}{ Tabela 2: Objetivos atrelados à saúde na escola na percepção dos professores } \\
\hline Categoria & Trechos das respostas \\
\hline $\begin{array}{c}\text { Prevenção de doenças e } \\
\text { autocuidado (40\%) }\end{array}$ & $\begin{array}{r}\text { "prevenção de doenças, surtos e epidemias; cuidados com a } \\
\text { saúde em diferentes épocas do ano"(P7) }\end{array}$ \\
$\begin{array}{c}\text { "prevenção de doenças; orientações sobre o modo de vida"(P6) } \\
\text { "promover hábitos saudáveis de higiene e alimentação nas }\end{array}$ \\
atividades diárias"(P9)
\end{tabular}

Embora exibidos em diferentes categorias, os objetivos da educação em saúde na escola, na percepção dos docentes, se complementam. A abordagem de hábitos de higiene e comportamentos preventivos são evidenciados em algumas respostas, reforçando nossa percepção relatada anteriormente, ao analisar as concepções de um enfoque comportamentalista, de que os problemas de saúde estão diretamente associados aos aspectos de higiene e autocuidado, e que cabe ao indivíduo a responsabilidade por sua própria saúde. Em complemento, alguns trechos destacados remetem a problemas e necessidades de saúde, seus determinantes e condicionantes como objeto de estudo. Com isso, é preciso considerar as influências do meio no qual a escola e a comunidade estão inseridas e evidenciar um escopo mais abrangente, que vai ao encontro das concepções biopsicossociais, ao considerar a possibilidade de a escola se firmar no cenário como um ambiente promotor da saúde.

Dessa forma, é importante resgatar que em um estudo anterior, realizado na mesma instituição de ensino, os pesquisadores observaram um quadro conceitual ingênuo, ainda em elaboração por parte dos docentes que, quando questionados sobre 
a promoção da saúde, manifestaram ideias reduzidas, opiniões contraditórias e alguns conceitos científicos equivocados (ILHA et al., 2014). Nesse sentido, as concepções sobre saúde observadas em nosso estudo revelam importantes avanços nos conceitos elaborados pelos educadores, principalmente no entendimento de que a relação entre saúde e educação perpassa distintas ações, e que envolvem sobretudo as ações educativas no contexto de promoção de saúde.

Essa modificação na compreensão dos docentes, com o incremento de processos formativos que consideram o contexto escolar, vão ao encontro das ideias defendidas por estudiosos que sugerem que as ações formativas, balizadas pela pesquisa, auxiliam na compreensão do contexto social no qual se desenvolve a ação educativa, assim como favorecem o desenvolvimento da consciência profissional, produzindo práticas que conduzem à transformação da atividade docente (ANDRÉ, 2017; LISITA; ROSA; LIPOVETSKY, 2017; THIOLLENT; COLETTE, 2014; ZEICHNER, 2012; KEMMIS; WILKINSON, 2012; IBIAPINA, 2008). Potencialidades da pesquisa nas práticas docentes também foram identificadas no estudo de llha et al. (2014), ao constatar que as intervenções colaborativas, sobre as quais se assentaram as reflexões sobre a prática pedagógica, contextualizadas com a realidade da comunidade escolar, desencadearam resultados satisfatórios na melhoria do ensino.

No final do primeiro encontro de aprofundamento teórico, a fim de identificar as demandas atuais percebidas pelos professores e fomentar os encontros subsequentes, foi alçado o seguinte questionamento: "Quais os temas sobre saúde mais relevantes, quando considerada a realidade dessa comunidade escolar?". As respostas foram analisadas de acordo com a frequência em que foram expostas. Assim, cada professor pôde elencar individualmente quantos temas percebesse necessário. Dentre os temas emergentes, a "alimentação saudável" foi mencionada em $66,6 \%$ das respostas; "saúde emocional" e "higiene", foram ambas referidas em $41,7 \%$ das respostas; seguidas de "atividade física" e "ingestão de água", ambas apontadas em 33,3\%; enquanto "uso do tabaco, álcool e outras drogas" foi mencionado em $6,67 \%$ das respostas.

Entre os temas relevantes para os professores, os aspectos relacionados a alimentação permearam a maior parte das respostas: "os problemas de saúde aqui na comunidade estão relacionados a maus hábitos alimentares" (P16); "muitas crianças ficam sozinhas em casa e acabam comendo de forma errada" (P2); "acho difíicil abordar a parte de alimentação, pois a maioria traz de casa comida processada, salgadinho e bolacha recheada" (P5); "tem que falar de alimentação e atividade física, mas é importante a participação da família também"(P12).

Através das falas dos docentes foi possível identificar o estabelecimento de vínculos entre a compreensão do contexto, as possibilidades e dificuldades que se colocam nas práticas educativas. Nesse sentido, as observações feitas pelos próprios docentes demonstraram possibilidades para identificação e organização dos objetivos e para a seleção de estratégias pedagógicas adequadas.

Dentre as estratégias utilizadas para abordar a importância da alimentação para a saúde, por exemplo, os professores relataram: "problematização e discussão em aula, elaboração de um cardápio semanal para o lanche, teatro de fantoches" (P2); "os alunos fizeram pesquisas sobre os tipos de alimentos e depois apresentaram a função de cada 
MENEZES, K. M.; RODRIGUES, C. B. C.; CANDITO, V. SOARES, F. A. A.

aos colegas" (P3); "construímos um painel: alimentação saudável $x$ alimentação não saudável utilizando recortes de jornais, revistas e catálogos de supermercados pesquisados pelos alunos"( $\mathrm{P} 8)$; "caminhada pela saúde até o parque dos quartéis para lanche solidário (cada um levou um prato)"(P10); "fizemos um café da manhã no qual os alunos trouxeram alimentos para um café na sala de aula antes dos estudos e depois dos estudos sobre alimentação saudável"(P11).

Neste estudo, os docentes se envolveram em processos de observação da realidade dos escolares e, a partir dessas observações, definiram os objetivos das atividades pedagógicas, a fim de orientar o desenvolvimento do pensamento crítico, para a construção, busca e utilização do conhecimento. Conforme Venturi et al. (2013), é fundamental que os professores tenham oportunidade de discutir e questionar a natureza e os objetivos da saúde na escola. Na perspectiva defendida por Mohr (2002), o objetivo da educação em saúde no contexto escolar deve ser o de instrumentalizar os estudantes para a reflexão, oferecendo-lhes autonomia de pensamento e ação, baseada em seu conhecimento e, assim, auxiliando a escolha de atitudes e comportamentos próprios que favoreçam sua saúde individual ou coletiva de maneira responsável, livre e esclarecida. Em complemento, Venturi et al. (2013) sinalizam que os comportamentos relacionados à saúde só podem ser modificados se as atividades escolares estiverem integradas ao cotidiano dos indivíduos. Em consonância, os objetivos e as estratégias pedagógicas propostos pelos docentes no presente estudo incentivaram a participação coletiva e buscaram desenvolver nos estudantes a capacidade de se colocar pessoalmente na construção das atividades, e assim auxiliar no desenvolvimento da criticidade acerca da sua realidade.

Quando questionados sobre as dificuldades para desenvolver os temas de saúde na escola, as respostas convergiram a três categorias, apresentadas na Tabela 3.

\begin{tabular}{|c|c|}
\hline Categoria & Trechos das respostas \\
\hline $\begin{array}{l}\text { Adequação aos conteúdos } \\
\qquad(15,38 \%)\end{array}$ & $\begin{array}{l}\text { "fazer a relação do conteúdo sobre saúde trabalhado na escola" } \\
\text { (P10) } \\
\text { "conhecimento sobre o assunto e adequação à disciplina"(P7) }\end{array}$ \\
\hline $\begin{array}{l}\text { Tempo/recursos para } \\
\text { planejamento }(38,46 \%)\end{array}$ & $\begin{array}{l}\text { "aqui na escola a conexão é bem limitada, o que dificulta um } \\
\text { pouco, já que o 'tempo' é pouco"(P5) } \\
\text { "falta tempo para planejamento, a internet da escola é muito fraca, } \\
\text { dificultando muito os trabalhos de pesquisa"(P6) }\end{array}$ \\
\hline Apoio Familiar (46,15\%) & $\begin{array}{c}\text { "o alcance nos hábitos familiares, na casa do aluno" (P13) } \\
\text { "a gente fala da alimentação saudável, mas a maioria continua } \\
\text { trazendo de casa comida processada, salgadinho e bolacha } \\
\text { recheada"(P 12); } \\
\text { "acho difícil trabalhar questões de higiene e alimentação, pois em } \\
\text { casa não temos respaldo, é complicado"(P15) }\end{array}$ \\
\hline
\end{tabular}

Após as reflexões, discussões e apontamentos dos docentes, realizados nos encontros de aprofundamento teórico, algumas dificuldades, necessidades e possibilidades puderam ser identificadas. Conforme manifestou um dos docentes: " $A$ 
escola contribui com o tratamento das informações, fomentando discussões e aprofundamento acerca dos conhecimentos necessários aos cuidados e manutenção da saúde. Porém, na maioria das vezes, não conseguimos passar dos conhecimentos teóricos e informações, pois, na prática, poucas ações se efetivam no dia a dia de nossos alunos, ou seja, eles têm informações, no entanto os hábitos acabam não se efetivando em mudança"(P10).

Dentre as principais dificuldades apontadas pelos docentes para o desenvolvimento das atividades escolares, a falta de apoio dos pais foi evidenciada na maior parte das respostas. Para Lisita; Rosa; Lipovetsky (2017), a capacidade de refletir criticamente sobre o ensino e o contexto social no qual estão inseridos é uma das potencialidades da articulação com a pesquisa, pois possibilita que os docentes identifiquem as condições do contexto familiar, social, institucional e histórica, conduzindo à educação de docentes reflexivos que considerem o ensino como prática contextualizada.

A partir da identificação da temática de alimentação saudável como emergente das observações e reflexões advindas do contexto escolar, quatro professoras das disciplinas de Educação Física, Ciências (duas) e Língua Portuguesa propuseram o desenvolvimento de projeto interdisciplinar que teve como questão problematizadora: "Como a alimentação pode influenciar na minha saúde?"

Diante dessa questão, os estudantes se envolveram em um processo investigativo durante o qual construíram seus diários alimentares. Após essa etapa, em sala de aula, os docentes abordaram fundamentos teóricos relativos à alimentação como fator de proteção ao surgimento de doenças. Em seguida, os educandos se envolveram no processo de elaboração das hipóteses de como tornar sua alimentação mais saudável, e construíram pirâmides alimentares. Essas etapas foram desenvolvidas na fase inicial do projeto, com o objetivo de identificar problemas e fomentar a conscientização.

Inserido nesse contexto, com objetivo de estimular os estudantes como elementos capazes de disseminar as informações no núcleo familiar e buscar o apoio e engajamento dos pais, alguns docentes, apoiados pela coordenação pedagógica, propuseram uma ação pedagógica, denominada o "Dia da Saúde na Escola”, direcionada à comunidade escolar. O "Dia da Saúde na Escola" foi realizado em um sábado, no mês de agosto de 2018. As ações implementadas nesse dia visaram despertar atenção e conscientização sobre estilo de vida saudável e comportamentos de risco para o surgimento de doenças, além de favorecer a participação e sensibilização das famílias, que foram convidadas a conhecer o projeto de ensino-aprendizagem desenvolvido pelos estudantes e docentes. Em complemento, foram oportunizadas avaliações do estado nutricional, controle glicêmico e pressão arterial sistêmica dos presentes, desenvolvidas com o apoio da equipe de profissionais da unidade de Estratégia da Saúde da Família (ESF), sediada no bairro.

As atividades desenvolvidas nesse dia propiciaram uma participação numerosa dos integrantes da comunidade escolar. Um aspecto importante evidenciado foi o envolvimento e empenho dos professores e da coordenação pedagógica na busca de suporte junto aos profissionais da ESF local, conjugando um imperativo de esforços e 
MENEZES, K. M.; RODRIGUES, C. B. C.; CANDITO, V. SOARES, F. A. A.

mudança conjunta para a construção de uma forma de pensar mais efetiva, valorizando as reais necessidades da comunidade escolar.

Para Couto et al. (2016), a concretização de ações de promoção da saúde no contexto escolar está apoiada nos professores que, com o papel de multiplicadores, devem estar capacitados para abordar o conceito de saúde, através do domínio de informações e de estratégias educativas para a construção integrada do conhecimento. Em conformidade, Freire sugere que "não é possível à escola, se, na verdade, engajada na formação de educandos educadores, alhear-se das condições sociais culturais, econômicas de seus alunos, de suas famílias, de seus vizinhos" (FREIRE, 1996, p. 26). Em consonância, para llha et al. (2014), os modelos de formação continuada que privilegiam a dimensão interativa/reflexiva, respeitando a relação entre pesquisadores-professoreseducandos, possibilitam o envolvimento efetivo dos docentes na sua própria formação, uma vez que não se limitam a ações pontuais, destinadas a suprir deficiências da formação inicial.

De acordo com Freire (1987), a partir do princípio da prática reflexiva, adota-se um conceito de formação docente que consiste no educador refletir sobre a própria prática em detrimento do conceito de formação continuada como processo de atualização, que se dá através de conhecimentos científicos e didáticos descontextualizados. De tal modo, a pesquisa permite acomodar a produção de saberes e a formação continuada de professores, visando à reestruturação e à reconstrução do trabalho em situações de ensino, a fim de promover avanços nos conhecimentos produzidos, tanto na academia como na escola, evidenciando o grande potencial da pesquisa enquanto ferramenta de ensino (KEMMIS; WILKINSON, 2012; ZEICHNER, 2012; THIOLLENT; COLETTE, 2014; IBIAPINA, 2008).

Nesta perspectiva, a aplicação de estratégias de ensino-aprendizagem, que impulsionem mudanças na maneira de pensar e repensar a escola e o currículo, além de favorecer a autonomia dos estudantes, é apontada por estudos que enfatizam as potencialidades da utilização de projetos de ensino-aprendizagem por permitir articular os conhecimentos científicos, colocando os sujeitos no centro do processo educativo (PINHEIRO, 2016; ARAÚJO, 2014; BENDER, 2014; BRAIDA, 2014). No âmbito escolar, a utilização de projetos tem se mostrado uma alternativa eficiente para aproximar o professor e os estudantes na busca da construção do conhecimento, pois além de contribuir com a reflexão e a organização da prática pedagógica, faz parte das necessidades e interesses da comunidade (ILHA et al., 2015; LIMA et al., 2019; VISINTAINER; SOARES, 2019). Esses estudos têm apontado sobretudo para necessidade de ressignificar o processo educativo, propiciando espaços de discussão e evidenciando a necessidade de envolvimento entre a família e a escola nesse processo.

No contexto deste estudo, tanto o projeto interdisciplinar que contemplou a temática da alimentação quanto o "Dia da saúde na escola" foram construídos a partir de discussões coletivas em todas as etapas, o que propiciou o trabalho colaborativo e coletivo entre gestores, pesquisadores, professores e estudantes. Com isso, foi possível considerar particularidades e especificidade da escola, assim como a necessidade dos conteúdos perpassarem a realidade dos educandos. Assim, as etapas de planejamento e desenvolvimento das ações evidenciaram a legitimidade dos processos de formação docente tendo a pesquisa como articuladora dos processos de ensino-aprendizagem, ao mesmo tempo em que promoveram ações de formação continuada aos docentes. 
Corroborando as ideias de Lüdke et al. (2016), a pesquisa pode ser um princípio educativo que possibilita a identificação de respostas para problemas já estabelecidos. Lisita, Rosa, Lipovetsky (2017), ao analisarem o potencial da pesquisa em criar condições que auxiliem os docentes a refletir criticamente sobre o ensino e o contexto social no qual estão inseridos, apontam para a necessidade de formar professores que pesquisem e produzam conhecimentos sobre seu próprio trabalho. Dentre as habilidades demandadas, as autoras citam o desenvolvimento de uma prática reflexiva através do trabalho coletivo, incorporando os pais e a comunidade na organização escolar no desenvolvimento de novos processos e instrumentos de ensino e de avaliação para compreender e contemplar diferentes processos cognitivos dos estudantes.

Em nosso estudo, os processos que permearam a pesquisa-ação consideraram a identificação das demandas locais, perpassando os encontros de aprofundamento teórico, planejamento, definição das metodologias e estratégias de trabalho, e favoreceram a interação entre educador e educando, mediante estratégias educacionais que visaram à aprendizagem compartilhada e à construção coletiva dos conhecimentos. Nesse sentido, por meio das falas dos docentes e do nosso acompanhamento das ações desenvolvidas, percebe-se que as atividades de pesquisa desenvolvidas pelos docentes visaram à melhoria das práticas pedagógicas ao buscar identificar e desenvolver estratégias de ensino adequadas ao perfil dos educandos e ao contexto escolar, ensejando, assim, a capacidade de refletir criticamente sobre sua realidade e intervir sobre ela.

\section{CONSIDERAÇÕES FINAIS}

Nossas observações, no contexto desta experiência, evidenciam que a efetividade da promoção da saúde no ambiente escolar ainda é um desafio, considerando a possibilidade de gerar ações adaptadas às realidades e demandas de cada contexto. Assim, é importante resgatar que os educadores e estudantes estão inseridos em um processo de reestruturação curricular, com a incorporação de projetos como alternativa didática à construção do conhecimento, tendo a pesquisa como articuladora no processo de ensino-aprendizagem. Com vistas à construção de práticas educativas que contemplem problemas imediatos da prática escolar, através do desenvolvimento de projetos interdisciplinares, permitir que a comunidade educativa possa identificar, controlar ou modificar os fatores que condicionam ou determinam a saúde individual e coletiva, assim como a mudança na percepção da situação de saúde.

Ao longo do processo formativo, os docentes se envolveram na observação da realidade dos escolares e definiram os objetivos das atividades pedagógicas, a fim de orientar o desenvolvimento do pensamento crítico para a construção, busca e utilização do conhecimento. Essas ações evidenciaram potencialidades desses momentos na práxis reflexiva sobre o ensino e o contexto social no qual estão inseridos.

Conforme já mencionado, embora não seja objetivo deste estudo detalhar os projetos interdisciplinares desenvolvidos, eles foram planejados dentro do currículo escolar, visando contemplar todo o período letivo. As atividades que solicitaram a participação do grupo familiar no desenvolvimento das tarefas evidenciaram, segundo a 
MENEZES, K. M.; RODRIGUES, C. B. C.; CANDITO, V. SOARES, F. A. A.

percepção dos docentes, a necessidade de esforços conjuntos para a consolidação de mudanças consistentes.

A pesquisa dos educadores apresentou-se como uma alternativa para melhoria do processo de ensino-aprendizagem, pois, além de contribuir com reflexões e organizações da prática pedagógica, favoreceu a identificação das necessidades e interesses da comunidade escolar e, de forma concomitante, se relacionou com o processo de formação continuada, garantindo o espaço e o tempo para formação dos professores. Nesse sentido, mesmo considerando que a pesquisa-ação é situacional, as modificações introduzidas na prática dos docentes foram constantemente avaliadas no decorrer do processo de ensino-aprendizagem e forneceram importante subsídios para a melhora na qualidade do ensino, permitindo ressignificar os processos pedagógicos. Assim, os procedimentos empregados durante a realização deste estudo apresentaram situações relevantes que apontam as possibilidades do uso desta metodologia para a formação e o trabalho docente, e demonstraram, sobretudo, as potencialidades do trabalho colaborativo entre escola e universidade a fim de promover espaço/tempo para a formação continuada dos docentes.

Artigo recebido em: 20/06/2020 Aprovado para publicação em: 13/10/2020

\section{RESEARCH AS AN ARTICULATOR OF PEDAGOGICAL PRACTICES: CONTRIBUTIONS TO A FORMATIVE PROCESS}

ABSTRACT: This study investigated the contributions of a proposal for continuing education with research as an articulator of the teaching-learning process. The methodological path was guided by action research and went through a formative process, developed with 25 teachers from a public school. The observations highlighted the research as a promising alternative for improving the teaching-learning process, as it allowed a significant space for dialogue between the participants and for the identification of the needs and interests of the school community. The processes employed promoted space and time for teacher training within the educational institution and highlighted the potential of school-university collaborative work.

KEYWORDS: Teacher training. Educational practices. Action research. Collaborative work

LA INVESTIGACIÓN COMO ARTICULADOR DE PRÁCTICAS PEDAGÓGICAS: CONTRIBUCIONES A UN PROCESO FORMATIVO

RESUMEN: Este estudio investigó los aportes de una propuesta de la educación continua con la investigación como articulador del proceso de enseñanza-aprendizaje. El camino metodológico fue guiado por la investigación acción y pasó por un proceso formativo, desarrollado con 25 profesores de una escuela pública de la red pública estatal de Rio Grande do Sul. Las observaciones destacaron la investigación como una alternativa promisoria para mejorar el proceso de enseñanza-aprendizaje, ya que permitió un importante espacio de diálogo entre los participantes y para la identificación de las necesidades e intereses de la comunidad escolar. Los 
procesos empleados promovieron espacios y tiempos para la formación docente dentro de la institución docente y destacaron el potencial del trabajo colaborativo escuela-universidad.

PALABRAS CLAVE: Formación del professorado, formación continua, investigación para la acción, trabajo colaborativo

\section{REFERÊNCIAS}

ANDRÉ, M. Pesquisa, formação e prática docente. In: ANDRÉ, M. (Org.). O Papel da Pesquisa na Formação e na Prática dos Professores. Campinas: Papiros, 2017. E-book.

ARAÚJO, U. F. Temas transversais, pedagogia de projetos e as mudanças na educação. São Paulo: Summus, 2014.

BARDIN, L. Análise de Conteúdo. São Paulo: Edições 70, 2011.

BENDER, W. N. Aprendizagem baseada em projetos: educação diferenciada para o século XXI. Porto Alegre: Penso, 2014.

BRAIDA, F. Da "Aprendizagem Baseada em Problemas" à "Aprendizagem Baseada em Projetos": estratégias metodológicas para o ensino de projeto nos cursos de Design à luz dos paradigmas contemporâneos. Actas de Diseño, v. 17, p. 142-146, 2014.

BRASIL. Referenciais para formação de professores. Brasília: Ministério da Educação: 174 p. 2002.

BRASIL. Ministério da Educação. Instituto Nacional de Estudos e Pesquisas Educacionais Anísio Teixeira (INEP). Censo Escolar, 2018. 2018. Disponível em: http://academia.qedu.org.br/censo-escolar/notas-tecnicas/. Acesso em: 13 abr. 2019.

BRASILa. Ministério da Educação. Política Nacional de Formação de Professores. 2017. Disponível em: http://portal.mec.gov.br/docman/outubro-2017-pdf/74041-formacaoprofessor-final-18-10-17-pdf/file. Acesso em: 05 abr. 2019.

BRASILb. Ministério da Educação. Secretaria da Educação Básica. Base Nacional Comum Curricular. 2017 Disponível em: http://basenacionalcomum.mec.gov.br/wpcontent/uploads/2018/02/bncc-20dez-site.pdf. Acesso em: 21 dez. 2018.

CARLAN, C. B. Influência de projetos pedagógicos interdisciplinares na atividade física habitual e no estado nutricional de escolares do ensino fundamental. 2016. Dissertação (Mestrado em Educação em Ciências, Química da Vida e Saúde), Universidade Federal do Rio Grande do Sul, Porto Alegre, RS, 2016. 
MENEZES, K. M.; RODRIGUES, C. B. C.; CANDITO, V. SOARES, F. A. A.

CHOW, K. C. K.; CHU, S. K. W.; TAVARES, N.; LEE, C. W. Y. Teachers as Researchers: A discovery of Their Emerging Role and Impact Through a School-University Collaborative Research. Brock Education Journal, v. 24, n. 2, p. 20-39, 2015.

COUTO, A. N.; KLEINPAUL, W. V.; BORFE, L.; VARGAS, S. C. et al. O ambiente escolar e as ações de promoção da saúde. Cinergis, v. 17, n. 4, Supl.1, p. 378-383, 2016.

DINIZ-PEREIRA, J. E. A pesquisa dos educadores como estratégia para construção de modelos críticos de formação docente. In: DINIZ-PEREIRA, J. E. e ZEINCHNER, K. M. (Org.). A pesquisa na formação e no trabalho docente. $2^{\text {a }}$ ed.: Autêntica. 2012. E-book.

FAGUNDES, T. B. Os conceitos de professor pesquisador e professor reflexivo: perspectivas do trabalho docente. Revista Brasileira de Educação, v. 21, n. 65, p. 281298, 2016.

FREIRE, P. Pedagogia da autonomia: saberes necessários à prática educativa. 25a ed. São Paulo: Paz e Terra, 1996.

FREIRE, P. Pedagogia do Oprimido. 17a ed. Rio de Janeiro: Paz e Terra, 1987.

GASPAROTTO, D. M.; MENEGASSI, R. J. Aspectos da pesquisa colaborativa na formação docente. Perspectiva, v. 34, n. 3, p. 948-973, 2016.

IBIAPINA, I. M. Pesquisa colaborativa: investigação, formação e produção de conhecimentos. Brasília: Liber Libro, 2008.

ILHA, P. V. Contribuições da pesquisa colaborativa na prática pedagógica docente, utilizando a aprendizagem de projetos como estratégia de ensino. 2014. Tese (Doutorado em Educação em Ciências, Química da Vida e Saúde), Universidade Federal de Santa Maria, Santa Maria, RS, 2014.

ILHA, P. V; LIMA, A. P. S; ROSSI, D. S; SOARES, F. A. A. Intervenções no ambiente escolar utilizando a promoção da saúde como ferramenta para a melhoria do ensino. Revista Ensaio, v. 16, n. 03, p. 35-53, set-dez, 2014.

ILHA, P. V.; LIMA, A. P. S.; VISINTAINER, D. S. R.; WOLLMANN, E. M. et al. Promoção da saúde a partir da aprendizagem por projetos. Atos da Pesquisa em Educação, 10, n. 1, p. 280-303, 2015.

KEMMIS, S.; WILKINSON, M. A pesquisa-ação participativa e o estudo da prática. In: DINIZPEREIRA, J. E. e ZEINCHNER, K. M. (Org.). A pesquisa na formação e no trabalho docente. $2^{\text {a }}$ ed.: Autêntica. 2012. E-book.

LIMA, A. P. S. Ensino multidisciplinar na melhoria do conhecimento nutricional no ensino fundamental. 2014. Dissertação (Mestrado em Educação em Ciências, Química da Vida e Saúde), Universidade Federal de Santa Maria, Santa Maria, RS, 2014.

Inter-Ação, Goiânia, v.45, n.3, p. 856-873, set./dez. 2020. Disponível em: <http://dx.doi.org/10.5216/ia.v45i3.63980>. 
LIMA, A. P. S. Formação continuada de professores de uma escola pública estadual visando a inserção das TICs em sala de aula. 2019. Tese (Doutorado em Educação em Ciências, Química da Vida e Saúde), Universidade Federal de Santa Maria, Santa Maria, RS, 2019.

LIMA, A. P. S.; ILHA, P. V.; SILVA, R. C. C. D.; SOARES, F. A. A. Aprendizagem por projetos no ensino fundamental: estratégia para entendimento da pirâmide alimentar. Research, Society and Development, 8, n. 1, p. e4781636, 2019.

LISITA, V.; ROSA, D.; LIPOVETSKY, N. Formação de professores e pesquisa: uma relação possível? In: ANDRÉ, M. (Org.). O Papel da Pesquisa na Formação e na Prática dos Professores. Campinas: Papiros. 2017. E-book.

LÜDKE, M., PUGGIAN, C., CEPPAS, F.; CAVALCANTE, R. L. A.; COELHO, S. L. B. O professor e a pesquisa. Campinas: Papirus, 2016.

LÜDKE, M. A complexa relação entre o professor e a pesquisa. In: ANDRÉ, M. (Org.). O Papel da Pesquisa na Formação e na Prática dos Professores. Campinas: Papiros. 2017. E-book.

MOHR, A. A natureza da educação em saúde no ensino fundamental e os professores de ciências. 2002. Tese (Doutorado em Educação), Universidade Federal de Santa Catarina, Florianópolis/SC.

NÓVOA, A. Os professores e a sua formação. Lisboa: Dom Quixote, 1992. p. 13-33. Disponível em: http://hdl.handle.net/10451/4758. Acesso em: 04 mar. 2019.

PINHEIRO, L. M. Pedagogia de Projetos. Rio de Janeiro: Clube de Autores. 2016. E-book.

RODRIGUES, C. B. C.; MENEZES, K. M.; CANDITO, V.; LOPES, L. F. D. et al. Determinantes em saúde e estilo de vida de escolares: estudo longitudinal. Research, Society and Development, 9, n. 2, p. e130922158, 2020.

RODRIGUES, C. B. C. Intervenções no ambiente escolar visando a promoção da saúde. 2020. (Doutorado) Universidade Federal de Santa Maria, Santa Maria, RS, 2020.

ROSSI, D. S. Imagem corporal, aspectos nutricionais e atividade física em estudantes. 2014. Dissertação (Mestrado em Educação em Ciências, Química da Vida e Saúde), Universidade Federal de Santa Maria, Santa Maria, RS, 2014.

SILVA, J.C.M. Formação continuada dos professores: visando a própria experiência para uma nova perspectiva. Revista Ibero-americana de Educação, v. 55, n. 3, p. 1-11, 2011.

THIOLLENT, M. Metodologia da pesquisa- ação. São Paulo, 18a ed. Cortez: 2011. 132p. 
MENEZES, K. M.; RODRIGUES, C. B. C.; CANDITO, V. SOARES, F. A. A.

THIOLLENT, M. J. M.; COLETTE, M. M. Pesquisa-ação, formação de professores e diversidade. Acta Scientiarum. Human and Social Sciences, v. 36, n. 2, p. 207-216, 2014.

VENTURI, T; PEDROSO, I; MOHR, A. Educação em Saúde na escola a partir de uma perspectiva pedagógica: discussões acerca da formação de professores. In: VI Encontro Regional Sul de Ensino de Biologia (EREBIO-SUL) 2013, Disponível em: http://santoangelo.uri.br/erebiosul2013/anais/wpcontent/uploads/2013/07/comunicacao/13437_130_Tiago_Venturi.pdf. Acesso em: 02 abr. 2019.

VISINTAINER, D. S. R. Oficinas Pedagógicas como estratégia para a promoção da saúde na formação docente continuada. 2018. Tese (Mestrado em Educação em Ciências, Química da Vida e Saúde), Universidade Federal de Santa Maria, Santa Maria, RS, 2018.

VISINTAINER, D. S. R.; SOARES, F. A. A. O desenvolvimento de estratégias de ensino para a promoçao da saúde na formação docente continuada. Revista Contexto \& Educação, 34, n. 109, p. 57073, 2019.

ZEICHNER, K. M. A pesquisa-ação e a formação docente voltada para a justiça social: um estudo de caso dos Estados Unidos. In: DINIZ-PEREIRA, J. E. e ZEINCHNER, K. M. (Org.). A pesquisa na formação e no trabalho docente. $2^{\text {a }}$ ed.: Autêntica. 2012. E-book.

Karla Mendonça Menezes: Licenciada e Bacharel em Educação Física, Especialista em Atividade Física, Desempenho Motor e Saúde e Mestra em Educação Física, todos pela Universidade Federal de Santa Maria (UFSM). Atualmente é aluna de Doutorado no PPG Educação em Ciências: Química da Vida e Saúde - UFSM e instrutora de esporte e lazer no Serviço Social do Transporte (SEST SENAT).

Orcid: http://orcid.org/0000-0002-7482-0648

E-mail: karlam.ef@gmail.com

Carolina Braz Carlan Rodrigues: Licenciada em Educação Física pela Universidade Luterana do Brasil, especialista em Treinamento, Musculação e Atividade Física na Faculdade Ingá (UNINGÁ - SM), mestre em Educação em Ciências: Química da Vida e Saúde na Universidade Federal do Rio Grande do Sul e Doutora em Educação em Ciências: Química da Vida e Saúde na Universidade Federal de Santa Maria.

Orcid: http://orcid.org/0000-0001-7115-0987

E-mail: carolina_carlan@hotmail.com

Vanessa Candito: Graduada em Ciências Biológicas. Mestranda no PPG em Educação em Ciências: Química da Vida e Saúde pela Universidade Federal do Rio Grande do Sul. 
Possui Especialização Lato Sensu em Ciências Ambientais pela URI - de Frederico Westphalen, e Especialização Lato Sensu em Educação Ambiental, pela UFSM/RS.

Orcid: http://orcid.org/0000-0003-4663-9590

E-mail: vanecandito@gmail.com

Félix Alexandre Antunes Soares: Doutor em Ciências Biológicas. Grupo de Estudos em Nutrição, Saúde e qualidade de vida. Professor Associado da Universidade Federal de Santa Maria. Docente do PPG em Educação em Ciências: Química da vida e Saúde (UFSM). Membro da Sociedade Brasileira de Bioquímica. Membro associado da Academia Brasileira de Ciências.

Orcid: http://orcid.org/0000-0002-6453-7902

E-mail: felix@ufsm.br

Este periódico utiliza a licença Creative Commons Attribution 3.0, para periódicos de acesso aberto (Open Archives Iniciative - OAI) 